\title{
Analysis of local ionospheric variability based on SVD and MDS at low-latitude GNSS stations
}

\author{
J. R. K. Kumar Dabbakuti, Venkata Ratnam Devanaboyina* and S. Ramesh Kanchumarthi
}

\begin{abstract}
Investigation of ionospheric anomalies during equatorial and low latitude is of major concern for modeling and global navigation satellite system (GNSS) applications. Total electron content (TEC) varies with the ionospheric conditions, which will lead to the errors in the global positioning system (GPS) measurements. It is therefore a method that is necessary to characterize the ionospheric anomalies for satellite-based navigation systems. In this study, characterization of ionospheric variations based on the singular value decomposition (SVD) and classical multidimensional scaling (MDS) methods was studied. The yearly and daily variations are decomposed from the GPS-TEC, international reference ionosphere (IRI) 2007 and IRI 2012 models TEC over the three low-latitude GNSS stations located at Koneru Lakshmaiah University (KLU-Guntur), Hyderabad and Bangalore, respectively. From the results, it is found that there is a strong correlation between GPS-TEC and IRI models. The correlation coefficient for the first three singular values is more than 0.86 . From this, it is possible to reconstruct more than $85 \%$ of the variability contained in global GPSderived VTEC data (for year 2013) by using only the first three modes. The semiannual variation has maximum value during March-April and September-October and has minimum value during June-July. It is observed that the annual variations have maximum value in summer and minimum value in winter, and the amplitudes decrease with increasing latitude. Further, opposite latitudinal asymmetry among annual and semiannual variations for three GNSS stations is noticed. SVD and MDS methods clearly show time-varying characteristics and the absence of the winter anomaly at low-latitude GNSS stations.
\end{abstract}

Keywords: GNSS, GPS, TEC, SVD, MDS, IRI

\section{Introduction}

Ionosphere is that part of upper atmosphere, extending from a height of 50 to $2000 \mathrm{~km}$ above the earth's surface. It is a region containing ionized gases affecting global navigation satellite system (GNSS) signals, leading to a change in total electron content (TEC) (Hunsucker and Hargreaves 2002). Further, GNSS signals will also be affected by geomagnetic, solar and other disturbances caused by propagation characteristics such as phase scintillations and amplitude fading (Yeh and Liu 1982; Aarons 1982). Because of this, there will be a reduction in the position navigation and the timing (PTN) parameter

\footnotetext{
*Correspondence: dvratnam@kluniversity.in Department of ECE, KLEF, K L University, Vaddeswaram, Guntur Dt, Andhra Pradesh, India
}

accuracies. There are many techniques used for the estimation of TEC variations using GNSS satellites (Komjathy 1997; Schaer 1999), among which grid-based ionospheric modeling is used for the study of ionospheric modeling over the Indian region (Skone 1998; Sarma, et al. 2009; Ratnam and Sarma 2012).

Precise ionospheric modeling provides better extraction of ionospheric data, from which the effects on satellite signals will improve the positional accuracy of GNSS receivers (Luo 2001; Cherniak et al. 2014). This leads to a significant approach to satellite-based navigation systems as well as space weather research. In current scenario, the study of ionosphere variability is more important for determining the future time epochs, and it is time-varying characteristics (Kazimirovsky et al. 2003; Laštovicka 2006). The time-varying nature of the ionosphere will 
have different characteristics for different latitudes (Misra and Enge 2006; Muella et al. 2011). Therefore, a better precise model is required to explain ionospheric characteristics at low-latitude GNSS stations. In this study, an attempt is made to describe ionospheric variability, accounting for daily, yearly, seasonal and solar variations of equatorial ionospheric anomaly (EIA) in global positioning system (GPS)-TEC based on singular value decomposition (SVD) and classical multidimensional scaling (MDS) methods over low-latitude GNSS stations ranging from $12.97^{\circ} \mathrm{N}$ to $17.41^{\circ} \mathrm{N}$ (Bangalore, KLU-Guntur and Hyderabad) during 24th solar cycle for the year 2013.

In addition, we observe the equinoctial irregularity in EIA crest with respect to annual, semiannual and equinox. This analysis at these GPS-TEC stations is useful for better understanding of the behavior of EIA effect over the low-latitude regions. Using MDS, hour-to-hour variability of individual cases was studied.

\section{Data and location}

Ionospheric characteristics for the year 2013 are considered for the three low-latitude GNSS stations in India, located at KLU-Guntur $\left(16.44^{\circ} \mathrm{N}, 80.62^{\circ} \mathrm{E}\right)$, Hyderabad $\left(17.41^{\circ} \mathrm{N}, 78.52^{\circ} \mathrm{E}\right)$ and Bangalore $\left(12.97^{\circ} \mathrm{N}, 77.59^{\circ} \mathrm{E}\right)$, respectively.

In this study, we have considered vertical TEC (VTEC) by converting slant TEC (STEC) using a mapping function (Langley et al. 2002), for which a single-layer ionospheric model is applied (Klobuchar 1996). KLU-Guntur GNSS station (GPS station, Novatel) recorded the STEC measurements for every one minute. IGS stations (Hyderabad and Bangalore) recorded the observations for every $30 \mathrm{~s}$ (http://sopac.ucsd.edu/). RINEX data are converted to STEC measurements using GPS-TEC software (Gopi 2010). In this model, the ionosphere is represented as thin shell at a given altitude $H_{\text {ion }}(350 \mathrm{~km})$. The point of intersection between the signal and the ionospheric shell is referred to as ionospheric pierce point (IPP) (Seeber 2003). The angle between the signal path and a line drawn from the center of the earth to the IPP is referred to as zenith angle $\alpha$. IPP latitude and longitudes are formulated based on the azimuth and elevation angles for a particular GPS satellite, height of the imaginary ionospheric shell $H_{\text {ion }}$ and GPS receiver position. GPS-TEC observations are considered as diverse line of sight from receiver to satellite referred as STECs and are obtained from receiver itself.

The relation between the VTEC, STEC and the elevation-dependent mapping function at IPP is given as (Seeber 2003)

$$
\mathrm{VTEC}=1 / M_{I} \times \mathrm{STEC}
$$

where

$$
M_{I}=\frac{1}{\cos \alpha^{l}}
$$

where $\alpha^{l}$ is the satellite's zenith angle at the IPP.

$$
\alpha^{l}=\arcsin \left(\frac{R_{\mathrm{E}}}{R_{\mathrm{E}}+H_{\text {ion }}} \sin \alpha\right)
$$

$M_{I}$, mapping function; $H_{\text {ion }}$, single-layer ionospheric $(350 \mathrm{~km}) ; R_{\mathrm{E}}$, mean Earth radius $(6378 \mathrm{~km}) ; \alpha$, satellite elevation angle.

Modified planar fit model is used to derive the VTEC at the zenith of the reference station coordinates and the daywise TEC profiles for every $24 \mathrm{~h}$ obtained for the year 2013 (Sarma, et al. 2009). The hourly electric field (Ey) data were taken from (http://omniweb.gsfc.nasa.gov/form/dx1.html) in order to figure out the variations of the ionosphere enhancements caused by electric field variations.

\section{SVD decomposition}

GPS-TEC time series of $X$ matrix is organized into hourly values $24 \times 365$ array, where hourly TEC data contain mean values of 24 per day. The rows of $X$ matrix are analogous to local time in hours $(h)-\mathrm{LT}(h=0,1$, ..., 23), and columns are analogous to days of the year (d) $(d=1,2, \ldots, 365)$. The SVD is one of the methods to decompose the given input matrix into a product of $U, S$ and $V$ variables. The $\mathbf{U}$ matrix represents the daily variation, and the $\mathbf{V}$ matrix represents the seasonal, yearly and solar variations. These variables represent the known patterns, when the input matrix is related to a set of continuous variables (Preisendorfer and Mobley 1988). SVD is accomplished by formulating the entire vertical TEC time-series data set into $m \times n$ matrix of $X$ (Parker 2004).

$$
X=U S V^{\mathrm{T}}
$$

$\mathrm{U}$ represents the $m \times n$ orthogonal matrix of $X X^{\mathrm{T}}$ where

$$
X X^{\mathrm{T}}=U S V^{\mathrm{T}} V S U^{\mathrm{T}}=U S^{2} U^{\mathrm{T}}
$$

$V$ represents the $n \times n$ orthogonal matrix of $X^{\mathrm{T}} X$ where

$$
X^{\mathrm{T}} X=V S U^{\mathrm{T}} U S V^{\mathrm{T}}=V S^{2} V^{\mathrm{T}}
$$

$S$ represents the $n \times n$ diagonal matrix (singular values)

$$
S=\operatorname{diag}\left(\sigma_{1}, \sigma_{2}, \ldots, \sigma_{n}\right)
$$

where $\sigma$ is a singular value of $X$, and its square is an eigenvalue of $X X^{\mathrm{T}}$ and ordered

$$
\sigma_{1} \geq \sigma_{2} \geq \cdots \geq \sigma_{n}
$$

The rank of a matrix $X \in R^{m \times n}$ can be written as

$$
X=\sum_{i=1}^{r} \sigma_{i} u_{i} v_{i}^{\mathrm{T}}=U S V^{\mathrm{T}}
$$


$U \in R^{m \times n}, V \in R^{n \times n}$ are the orthogonal matrixes, and $S$ is diagonal matrix.

In the above, $r$ turns out to be the rank of $X$ and equivalent to the number of nonzero singular values.

\section{Classical multidimensional scaling method}

Classical MDS method compares the dissimilarities for the given input matrix with I series and N-dimensional coordinate matrix (Borg and Groenen 2005). The number of GPS-TEC observations in each series of a given matrix is $L$. GPS-TEC time series of $X$ is organized by $N<I, N \leq L$, and the hourly TEC data series contains mean values of 24 per day. Considering, rows as twenty-four observations a day ( $h=0,1, \ldots, 23)$ and column as monthly median contains 12 months, so that the number of input series $I$ is equal to 24 and the sampling number $L$ equal to 12 . Classical MDS can be performed by the following steps: First we standardize all the data series and then obtain the dissimilarity matrix by calculating the connectivity of the data series. Finally, we consider the dissimilarity matrix as the input to the classical MDS and compute the coordinate matrix, from which the coordinate matrix is computed and visualized the connectivity by selecting the number of dimensions. The standardization is given as (Shi et al. 2015).

$$
X_{i}=x_{i}=\frac{X_{i}-\bar{X}_{i}}{\sigma_{i}}
$$

$\bar{X}_{i}$ is the average, and $\sigma_{i}$ is the standard deviation.

GPS-TEC variables in the data set are centered with respect to the means 0 and standard deviations 1 of different ranges. Based on these GPS-TEC data, the connectivity is calculated among the two standardized time series $x_{i}$ and $x_{j}$ based on Euclidean distance

$$
d_{i j}=\sqrt{\sum_{k=1}^{L}\left(x_{i k}-x_{j k}\right)^{2}}
$$

where $x_{i k}$ is $k$ th sample of $x_{i}$.

The standardized series of GPS-TEC monthly median is considered for the understanding of the ionospheric variability, by considering the connectivity between two series and their correlation with respect to local time.

Multivariate statistical analysis is considered for the dissimilarity $\delta$ to describe the relationship between the two series. Accordingly, the lower the dissimilarity is, the higher the connectivity is and vice versa. So this distance can also be used to depicting the dissimilarity among two series, i.e., $\chi_{i, j}=d_{i j}$, can be organized by a matrix as

$$
\delta=\left(\begin{array}{cccc}
\chi_{1,1} & \chi_{1,2} & \cdots & \chi_{1, I} \\
\chi_{2,1} & \chi_{2,2} & \cdots & \chi_{2, I} \\
\vdots & \vdots & \ddots & \vdots \\
\chi_{I, 1} & \chi_{I, 2} & \cdots & \chi_{I, I}
\end{array}\right)
$$

Further, the series can be represented by a single-point multidimensional connectivity map and the dissimilarity matrix $\delta$, which is equal to the distance between any pair of points. This exactly represents the MDS method, specified by $\delta$ to determine the $N$ vectors $y_{i}, \ldots, y_{N} \in \Re^{N}$ (Shi et al. 2015).

$$
\left\|y_{i}-y_{j}\right\| \approx \delta_{i, j}, \quad i, j \in N,
$$

$\left\|y_{i}-y_{j}\right\|$ is the Euclidean distance.

Consider 2 or 3 dimension to represent the vectors $y_{i}$ to achieve the visualization of the similarities between the pair of $I$ units. Here, $\left\|y_{i}-y_{j}\right\|$ are not unique, and they may randomly be translated, rotated or reflected with the Euclidean distance. However, these transformations will not affect the pairwise distances of $\left\|y_{i}-y_{j}\right\|$.

MDS is formulated as an optimization problem to determine the vectors $y_{i}$, where $y_{i}, \ldots, y_{N}$ are initiated as a minimized cost function.

$$
\min _{y_{1}, \ldots, y_{N}} \sum_{i<j}\left(\left\|y_{i}-y_{j}\right\|-\delta_{i, j}\right)^{2}
$$

Optimization can be achieved by the Euclidean distance, and the minimized cost function can be analyzed in terms of matrix eigenvalue decomposition such as the principle component analysis.

The decomposition of GPS-TEC series can be ordered as a linear combination of separable modes and the vectors $y_{i}$ (Chatfield and Collins 1980) given as:

$$
X_{i k}=\sum_{l=1}^{N} W_{l}, g_{k l}, f_{i l}
$$

where $W_{l}$ represents the variable weight, $g_{k l}$ represents the mode coefficients and $f_{i l}$ represents mode component score, with the orthonormality limit.

$$
\left\langle g_{k l} g_{k m}\right\rangle=\left\langle f_{k l} f_{k m}\right\rangle= \begin{cases}0, & l \neq m, \\ 1, & l=m,\end{cases}
$$

where $\left\langle g_{k l} g_{k m}\right\rangle$ is the ensemble averaging, and the weights are sorted out in descending order $W_{1} \geq W_{2}, \ldots, W_{N}, \geq 0$, and higher weights correspond to mode observations that represent the features shared by many observables.

Proportion of variance accounted by $l$ th mode is given as

$$
V_{l}=\frac{W_{l}^{2}}{\sum_{m=1}^{N} W_{m}^{2}}
$$

According to Chatfield and Collins (1980), the coordinate units along the $l$ th axis of the connectivity map are represented by $W f_{i l}$ 


$$
y_{i}=\left(W_{l} f_{i l}, \ldots, W_{N} f_{i N}\right)
$$

In this study, the first two component modes are used to describe the connectivity. The familiar characteristic shared by units lying along the $l$ th axis is represented by the series of $g_{k l}$ and associated with these varying axes; these series are verified to depict the significance of the axes.

\section{Results and discussions}

GPS-TEC and international reference ionosphere (IRI) model data for the year 2013 are considered to study the ionospheric variability for three geographic locations. The results represent ionospheric variability based on SVD, MDS and IRI models over the low-latitude regions. There are many reports revealing that GPS-TEC model and IRI model data are highly variable at low latitudes and equatorial regions (Adeniyi et al. 2003; Zhang et al. 2004; Muella et al. 2011). As shown in "Fig. 1," the ionospheric variability based on the SVD method is decomposed into hour of the day (HOD) $U$ and day of the year variations (DOY) $V$. In "Fig. 1," first singular value $U_{1}$ represents the daily signal for all the three GNSS stations, and it is observed that $U_{1}$ of KLU (Guntur) and Hyderabad GNSS stations are exactly correlated with IRI models, whereas $U_{1}$ of Bangalore shows some difference in similarities with that of IRI models.

It is observed that there are minor variations in second and third singular values of $U_{2}$ and $U_{3}$, which may be attributed to the larger disturbances in plasma structure of the ionosphere due to magnetic storms produced by electric field and neutral winds (Tanaka 1986; Greenspan et al. 1991). Further, ionospheric sunrise enhancements in second singular value of $U_{2}$ of IRI models are observed. "Figure 1" reveals that there is an increase, starting about $3.00 \mathrm{LT}$ and reaching a maximum at $5.00 \mathrm{LT}$, thereby reaching a minimum at around $13.00 \mathrm{LT}$ and then start increasing from $13.00 \mathrm{LT}$ onward and attaining a maximum at around $17.00 \mathrm{LT}$. It can be noticed that KLU (Guntur) and Hyderabad regions of $U_{2}$ show some minor deviations in similarities with that of IRI models. These phenomena describe the ionospheric sunrise enhancement and sunset enhancement, respectively (Schunk and Nagy 2009; Liu et al. 2004). In KLU-Guntur, Hyderabad and Bangalore, the enhancements of the electric field variations, showing a variability of electric fields and ionospheric densities in second and third singular values of $U_{2}$ and $U_{3}$, are observed as shown in "Fig. 2." The second singular value of $U_{2}$ of KLU (Guntur), showing a depletion around 3.00 LT and an enhancement at $13.00 \mathrm{LT}$, is noticed. The same phenomena are also observed in $U_{3}$ of Hyderabad and Bangalore. These sunrise enhancements correlate with that of pre-reversal enhancements (PRE) as observed in vertical drifts, which is a regular phenomena observed by ground- and space-based instrument near sunset hours in the equatorial ionosphere (Kelley et al. 2014). Further, the vertical drifts are accompanied by eastward drifts (Aggson et al. 1995). The electron density of the ionosphere can be affected by the solar activity, which in turn impacts the TEC variability of day-to-day, seasonal and yearly variations. These observations are shown in "Fig. 1," as $V_{1}, V_{2}$ and $V_{3}$, respectively, for three GNSS stations. The solar radio flux F10.7 is a sign for solar activity and correlates well with the sunspot number (Tapping 1987). First, singular value of $V_{1}$ replicates the solar effect on ionospheric TEC observations, which reflects on their yearly variations and is clearly illustrated in "Fig. 3." Solar activity F10.7 in solar cycle 24 in 2013 has a marked correlation with that of GPS-TEC. We observed the KLU-Guntur and Hyderabad stations have shown less correlation during autumn and spring months with F10.7 and immense correlation with Bangalore station. These dissimilarities among GPS-TEC and IRI model TEC are found to be solar and latitudinal dependent.

The second and third singular values of $V_{2}$ and $V_{3}$ show short-term periods such as seasonal and semiannual variations. The semiannual variation during EIA crest in TEC is changing due to magnetic field geometry and solar zenith angle. In general, ionospheric electron density is balanced by means of solar photoionization and recombination process, whereas the localized enhancements and depletions are affected by electromagnetic forcing (Wu et al. 2004). "Figure 1" of second singular value $V_{2}$ shows the maxima during the equinox months and their minima during the summer and winter. We can observe that the semiannual variation is seen with two maxima occurring in both spring and autumn equinox for Hyderabad and Bangalore stations. During these months, photoelectrons at the equator are enhanced due to the subsolar points, and this enhancement is due to the eastward electrojetassociated electric field (Wu et al. 2004, 2008). But KLUGuntur shows some dissimilarity with IRI model data during summer and winter. During these months (winter and summer), photoelectrons at the equator diminish due to the subsolar points away from the equator and moves to the higher latitudes. Similar types of seasonal and annual variations in EIA crest have been studied in Taiwan and Brazil (Huang and Cheng 1996; Muella et al. 2011). During the winter solstice period, we observed the maxima in December, which is slightly higher than September. This can be attributed to winter anomaly. But in January 2013, winter solstice is remained subdued. Recent studies using GIM TEC model values have the same immense detections (Dashora and Suresh 2015; Raghunath and Ratnam 2015). The correlation between GPS-TEC and IRI model data for the first three singular 

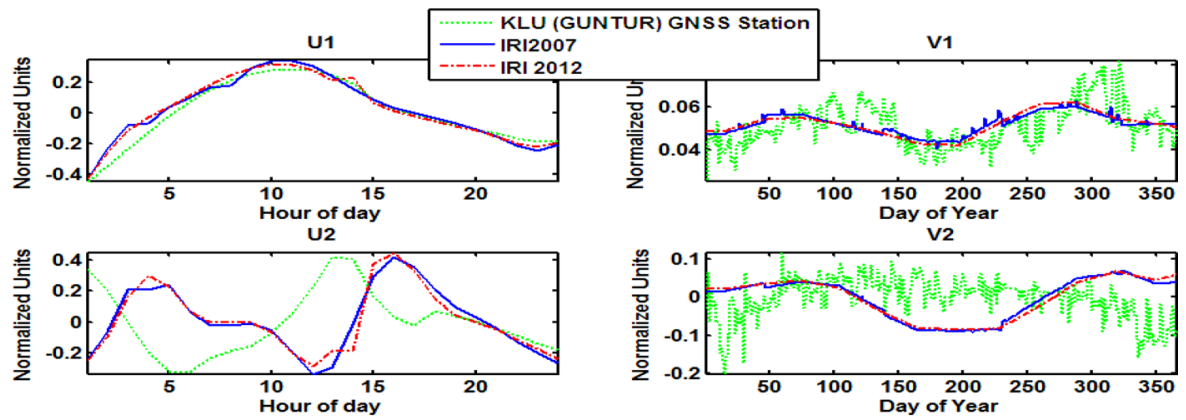

V2
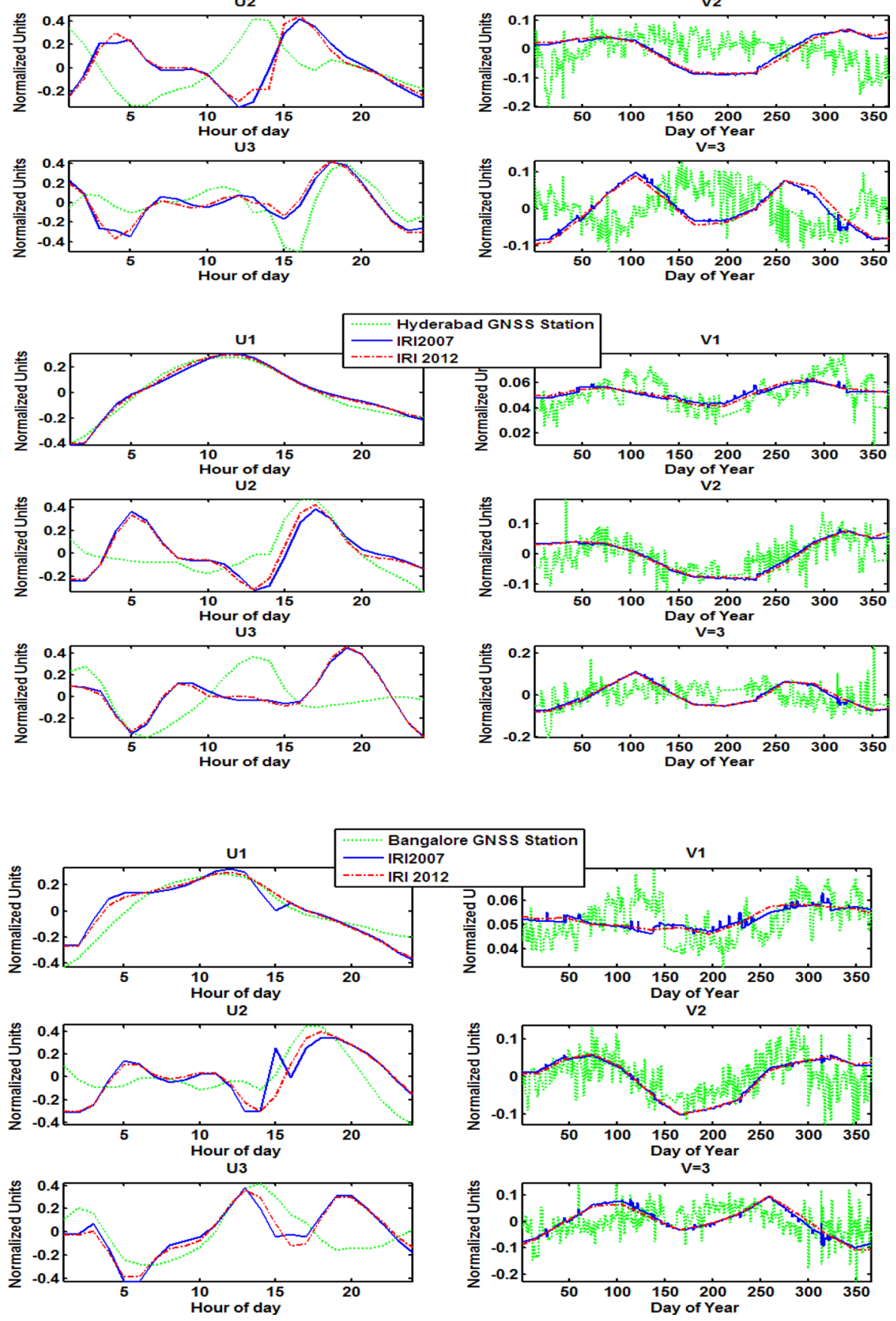

Fig. 1 Time variations of GPS-TEC and IRI model data based on the first three singular values at three GNSS stations 

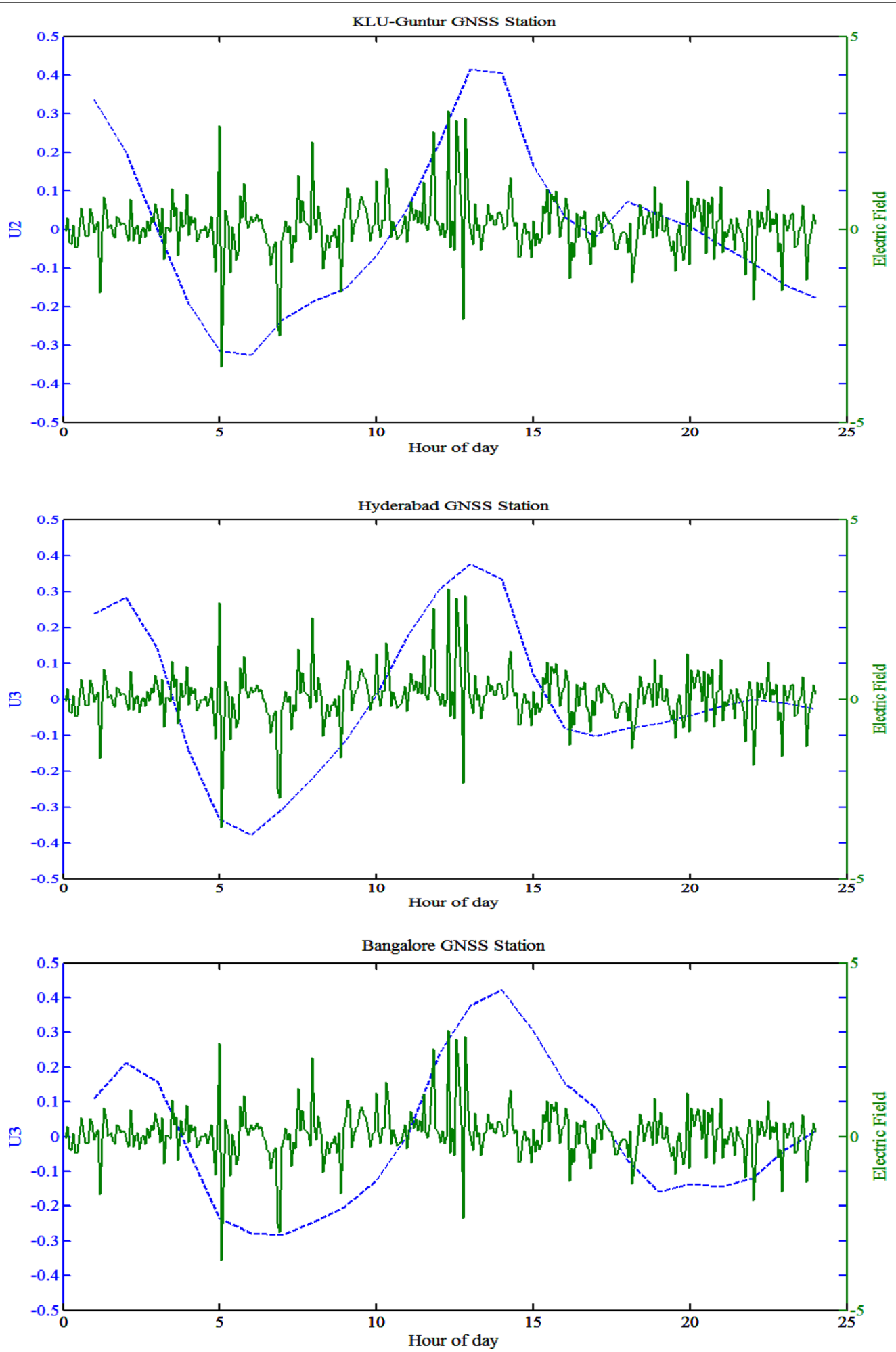

Fig. 2 Variations between GPS-TEC and electric fields for the second and third singular values of $U_{2}$ and $U_{3}$ at three GNSS stations 

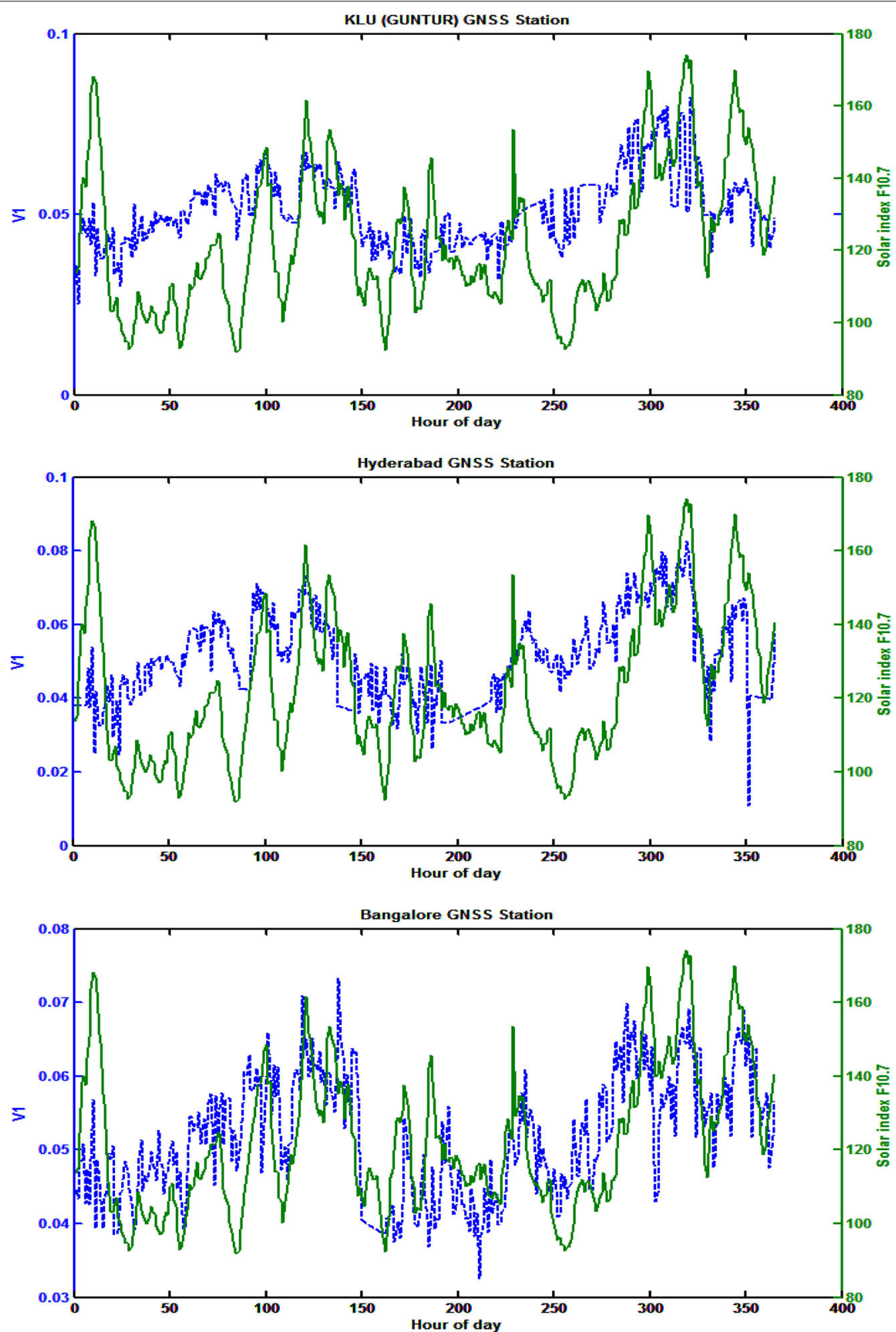

Fig. 3 Variations between GPS-TEC and solar index F10.7 for the first singular value $V_{1}$ at three GNSS stations 
values is illustrated in Table 1. Further, it is observed that there is no specific recognizable pattern from fourth singular values onwards.

The hour-to-hour ionospheric variability was analyzed based on MDS for three GNSS stations. Considering the first three dimensions of the connectivity map, it is seen that there is more than $87 \%$ of the variance. Out of three dimensions, first two dimensions in the connectivity map are taken to be at least $85 \%$ of the total variance and are explained for the ionosphere variability. Similar kind of analysis can be carried out using PCA (Meza et al. 2015).

Table 1 Correlation coefficients for the first three singular vales obtained from the three GNSS stations data sets and IRI models

\begin{tabular}{|c|c|c|c|}
\hline Singular values & 1 & II & III \\
\hline \multicolumn{4}{|c|}{ Corr. Coef. for three GNSS stations with IRI models } \\
\hline KLU (Guntur) and IRI-2007 & 0.90 & 0.89 & 0.88 \\
\hline KLU (Guntur) and IRI-2012 & 0.91 & 0.90 & 0.89 \\
\hline Hyderabad and IRI-2007 & 0.89 & 0.86 & 0.89 \\
\hline Hyderabad and IRI-2012 & 0.90 & 0.89 & 0.87 \\
\hline Bangalore and IRI-2007 & 0.89 & 0.87 & 0.88 \\
\hline Bangalore and IRI-2012 & 0.90 & 0.88 & 0.89 \\
\hline
\end{tabular}

Their corresponding modes $g_{k l}$ are shown in "Fig. 4," and subscripts $k$ and $l$ stand for the month and dimension.

The modes of the first dimension $g_{k 1}$ illustrate the semiannual and seasonal variations, and the second dimension $g_{k 2}$ illustrates the annual variation at three GNSS stations. Further, the third and following dimensions are having the quantity of variances; their contributions are weaker than the first two dimensions.

These dimensions of variance explain the latitudinal dependence. Table 2 illustrates the percentage of semiannual and annual variations of $g_{k 1}$ and $g_{k 2}$. During solar cycle 24 in 2013, equatorial ionization anomaly (EIA) leads to affecting annual and semiannual.

"Figure 4" shows the latitudinal dependence of annual, semiannual and seasonal variations, having maxima in equinox months of October and April and minima in the months of June and July during the summer, while in winter (December and July) somewhat higher values than summer and lower values at equinox months for the three GNSS stations. We observe that the first mode coefficient had maxima at 0.46 and minima at -0.3 for KLU-Guntur and 0.39 and -0.4 for Hyderabad during April and June months. But Bangalore station shows a diminutive dissimilarity with other two stations and having maxima at 0.36 and minima at -0.4 during April and July months, respectively. Second dimension $g_{k 2}$ represents the annual
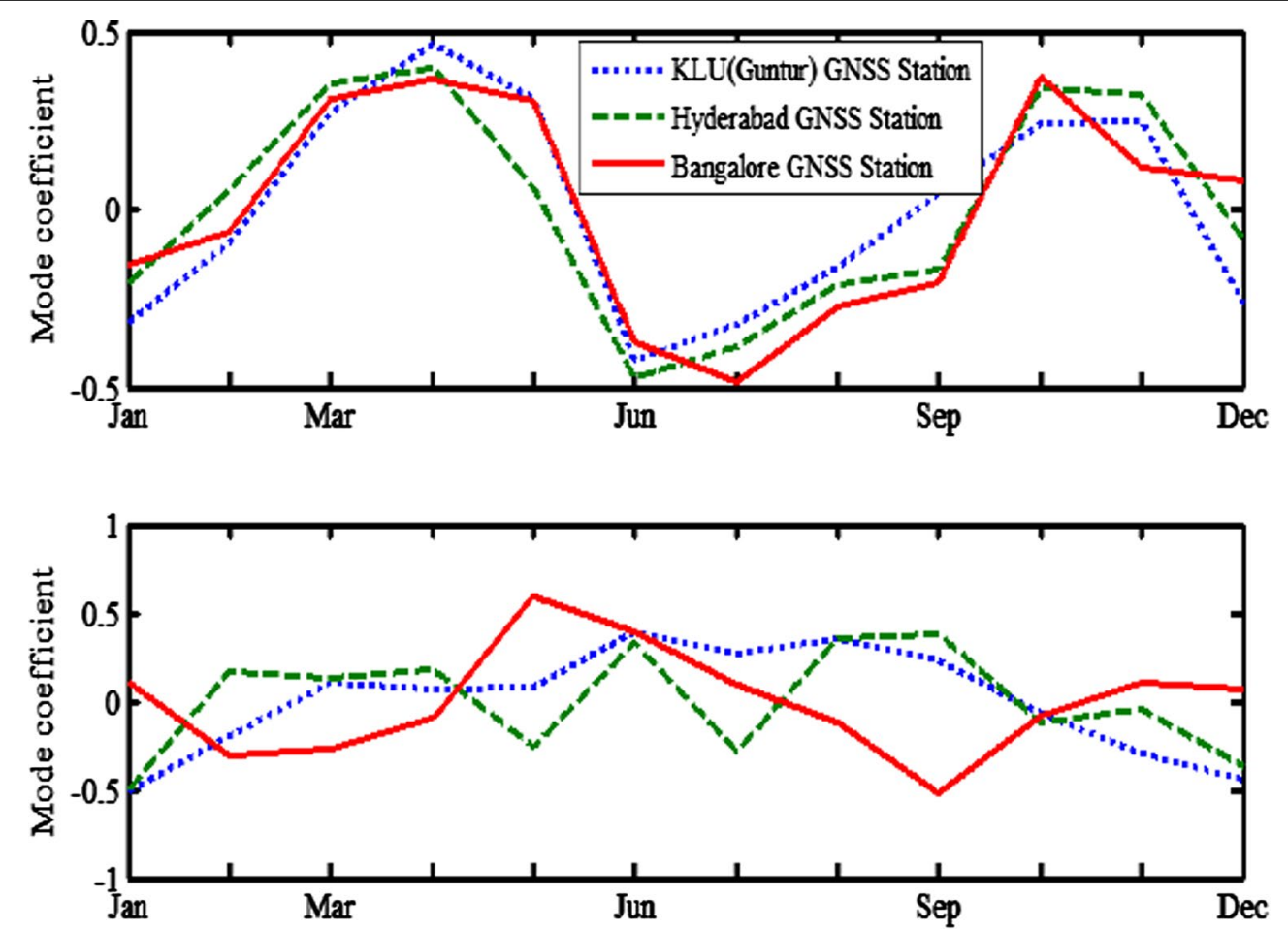

Fig. 4 Time variation for the first two mode coefficients from the three GNSS stations data sets. The upper panel represents the mode coefficient $g_{k 1}$, and the bottom panel represents the mode coefficient $g_{k 2}$ 
Table 2 Fractional variance for the first three dimensions of the connectivity map and summed up

\begin{tabular}{|c|c|c|c|}
\hline Dimensions & $\begin{array}{l}\text { KLU (Guntur) } \\
\left(16.44^{\circ} \mathrm{N}, 80.62^{\circ} \mathrm{E}\right)\end{array}$ & $\begin{array}{l}\text { Hyderabad } \\
\left(17.41^{\circ} \mathrm{N}, 78.52^{\circ} \mathrm{E}\right.\end{array}$ & $\begin{array}{l}\text { Bangalore } \\
\text { E) }\left(12.97^{\circ} \mathrm{N},\right. \\
\left.77.59^{\circ} \mathrm{E}\right)\end{array}$ \\
\hline 1 & 71.42 & 74.3 & 69.90 \\
\hline 2 & 13.9 & 12.22 & 15.26 \\
\hline 3 & 3.8 & 4.89 & 2.63 \\
\hline SUM & 89.12 & 91.41 & 87.79 \\
\hline
\end{tabular}

variations, and the amplitudes decreases with increasing latitude. Similar findings observed in SVD for winter anomaly are also observed in MDS. Further, we observed opposite latitudinal asymmetry among annual and semiannual variations for three GNSS stations. Zhao et al. (2008) and Natali and Meza (2011) also reported the similar findings for high solar activity year.

The results in Table 2 and "Fig. 4" clearly represent hour-to-hour ionospheric variability. In addition, hourto-hour connectivity maps are shown in "Fig. 5." Each dot represents the local time at a certain instant. Axis-1 and axis- 2 represent coordinates of these dots, which are determined by $W_{1} f_{i 1}$ and $W_{2} f_{i 2}$, respectively. Their corresponding modes $g_{k 1}$ and $g_{k 2}$ represent the semiannual and annual variations. Axis- 1 coordinates indicate the amplitudes of the semiannual components, and similarly axis-2 coordinates indicate the amplitudes of the annual components. As the ionospheric condition is local time dependent, some ordered connections are obtained from the dots of the connectivity map. These dots are divided into four groups based on coordinates and the local time. Each group corresponds to a time interval of a day. The ionospheric features of these groups are TEC maxima, minima, TEC enhancement and depletions. The first group corresponds to the TEC maximum period, which is at noon hours. These are represented on the right side part of the axis-1, which are mainly of high TEC values in a day. The second group corresponds to the TEC minimum period, which is around midnight hours. These are represented on the left side part of axis 1, which are of low TEC values in a day. Their positive and negative coordinates of axis-1 refer to annual variation of summer maximum and minimum types, respectively. The middle area around zero is represented by remaining two groups, which shows the features of TEC

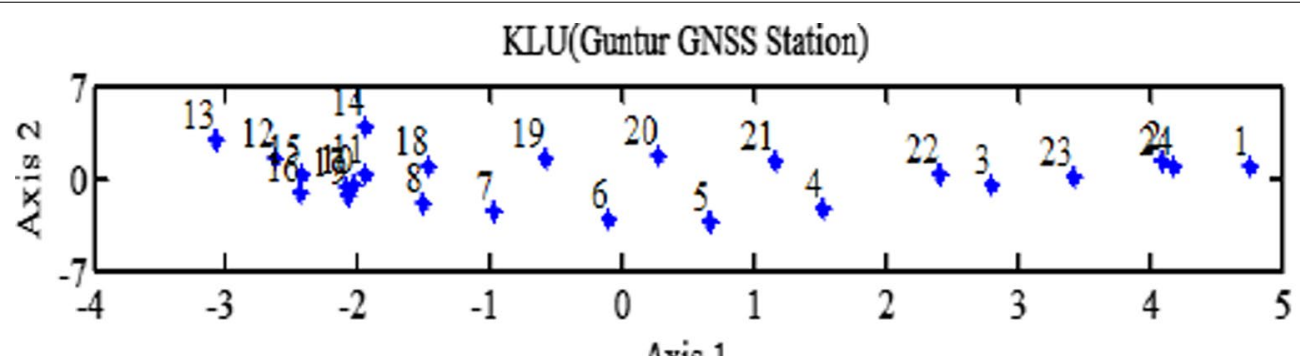

Axis 1
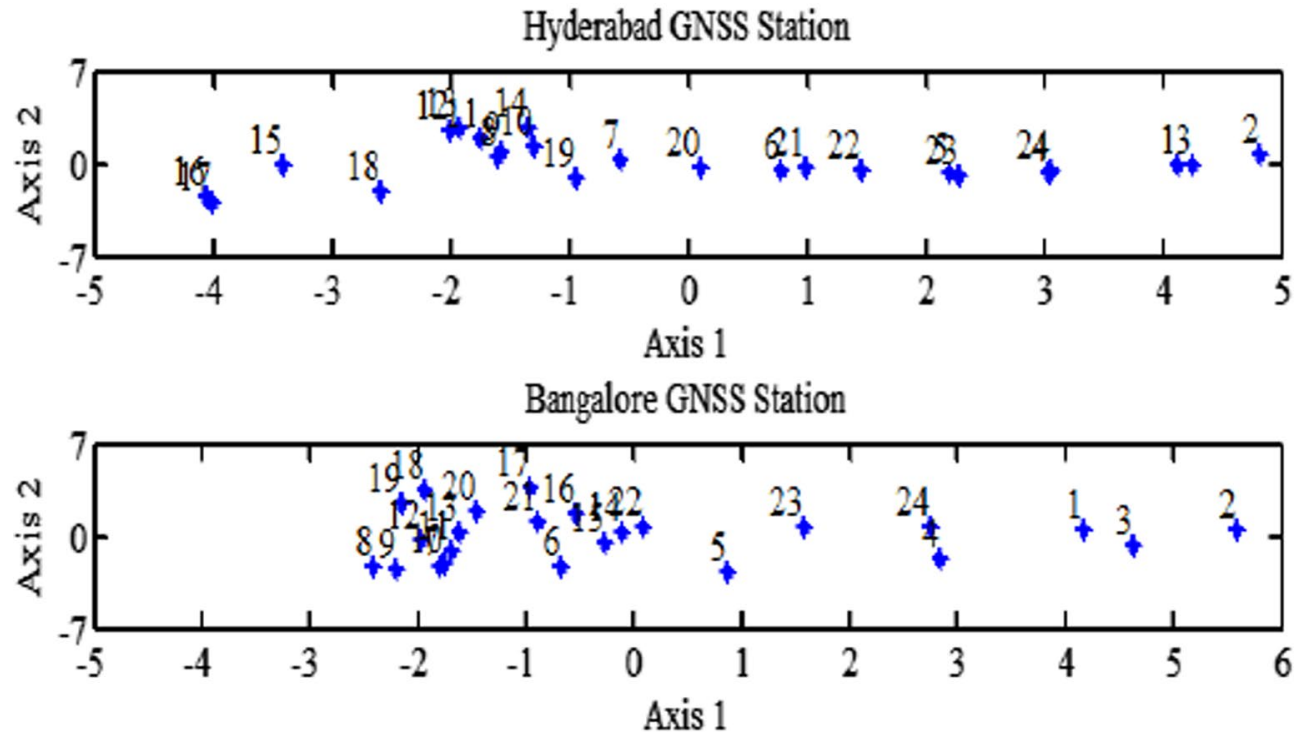

Fig. 5 Hour-hour connectivity maps of GPS-TEC at three GNSS stations 
enhancement and depletion periods near sunrise and sunset hours, respectively. Similarly, the axis-2 coordinates on either side of zero represent the semiannual variations and their amplitudes showing high TEC values in a day, whereas the dots around the midpoint (zero) represent the reference values with low amplitude in the seminal variations.

The connectivity between the two units among the three GNSS stations shows some latitudinal dependencies and is observed in "Fig. 5" at three GNSS stations. As mentioned above, the connectivity map can be characterized into four periods representing the midnight, sunrise, noon and sunset with respect to LT. During midnight and noon hours, the connectivity is high because the conditions of the ionosphere are changing due to the dynamic equilibrium between photochemical production and loss processes (Qian et al. 2008; Hunsucker and Hargreaves 2002). Whereas during midnight hours the diurnal connectivity patterns differ for Bangalore GNSS station when compared with that of other two GNSS stations, during sunrise and sunset hours the connectivity is low and the condition is unstable due to rapid enhancements in electron densities occurring in the ionosphere. During sunrise hours, we observed that the diurnal connectivity patterns for KLU-Guntur and Hyderabad are appeared to be approximately the same, whereas with Bangalore station the dissimilarity mainly occurs near midnight when compared with that of other two stations. This rapid change in the ionosphere is mainly due to solar ionizing irradiation, solar heating, wind and electric currents showing uncertainty in hour-to-hour connectivity for the three GNSS stations.

\section{Conclusions}

SVD and MDS methods have been implemented to characterize the ionospheric variability using the GPS-TEC data with different latitudes. The variations in daily-averaged GPS-TEC are represented based on the first three modes. It is observed that there is high degree of accuracy and linear correlation between GPS-TEC data and IRI models. The singular values of $U$ and $V$ represent the diurnal and long-term variations (seasonal, yearly and solar variations). Hour-hour ionospheric variability can be explained by the classical MDS. The variability at sunrise, sunset, noon and midnight hours at three GNSS stations is clearly shown. The outcome of the present analysis would be useful for perceptive and precision of diminutive time forecasting of the ionosphere.

\section{Authors' contributions}

JRKKD collects the GPS-TEC and IRI model data sets for year of 2013 and prepared the manuscript; VRD gave the idea how to the apply the given data sets to SVD and MDS methods; and SRK evaluates the manuscript. All authors read and approved the final manuscript.

\section{Acknowledgements}

Authors would like to express their thanks to the Department of Science and Technology, New Delhi, India, for funding this research through the SR/S4/ AS-91/2012and SR/FST/ESI-130/2013(C) FIST program. Thanks are due to the anonymous reviewers and also to the editors for their valuable comments for improving the quality of this study.

Received: 5 October 2015 Accepted: 19 May 2016

Published online: 01 June 2016

\section{References}

Aarons J (1982) Global morphology of ionospheric scintillations. Proc IEEE 70(4):360-378

Adeniyi JO, Bilitza D, Radicella SM, Willoughby AA (2003) Equatorial F2-peak parameters in the IRI model. Adv Space Res 31(3):507-512

Aggson TL, Herrero FA, Johnson JA, Pfaff RF, Laakso H, Maynard NC, Moses JJ (1995) Satellite observations of zonal electric fields near sunrise in the equatorial ionosphere. J Atmos Terr Phys 57(1):19-24

Borg I, Groenen PJ (2005) Modern multidimensional scaling: theory and applications. Springer, Berlin

Chatfield C, Collins AJ (1980) Introduction to multivariate analysis. Chapman and Hall, London. ISBN:0-412-16030-7

Cherniak I, Zakharenkova I, Krankowski A (2014) Approaches for modeling ionosphere irregularities based on the TEC rate index. Earth Planets Space 66(1):1-5

Dashora N, Suresh S (2015) Characteristics of low-latitude TEC during solar cycles 23 and 24 using global ionospheric maps (GIMs) over Indian sector. J Geophys Res Space Phys 120(6):5176-5193

Gopi S (2010) Rinex GPS-TEC program, version 1.45. Boston College, Chestnut Hill

Greenspan ME, Rasmussen CE, Burke WJ, Abdu MA (1991) Equatorial density depletions observed at $840 \mathrm{~km}$ during the great magnetic storm of March 1989. J Geophys Res Space Phys 96(A8):13931-13942

Huang YN, Cheng K (1996) Solar cycle variations of the equatorial ionospheric anomaly in total electron content in the Asian region. J Geophys Res Space Phys 101(A11):24513-24520

Hunsucker RD, Hargreaves JK (2002) The high-latitude ionosphere and its effects on radio propagation. Cambridge University Press, Cambridge

Kazimirovsky E, Herraiz M, De la Morena BA (2003) Effects on the ionosphere due to phenomena occurring below it. Surv Geophys 24(2):139-184

Kelley MC, Rodrigues FS, Pfaff RF, Klenzing J (2014) Observations of the generation of eastward equatorial electric fields near dawn

Klobuchar JA (1996) lonospheric effects on GPS. In: Spilker JJ, Parkinson BW (eds) Global positioning system: theory and applications, vol 1. AIAA, Washington, pp 485-515

Komjathy A (1997) Global ionospheric total electron content mapping using the global positioning system. Doctoral dissertation, University of New Brunswick

Langley R, Fedrizzi M, Paula E, Santos M, Komjathy A (2002) Mapping the low latitude ionosphere with GPS. GPS World 13(2):41-46

Laštovička J (2006) Forcing of the ionosphere by waves from below. J Atmos Solar Terr Phys 68(3):479-497

Liu L, Wan W, Ning B (2004) Statistical modeling of ionospheric foF2 over Wuhan. Radio Sci 39:RS2013. doi:10.1029/2003RS003005

Luo N (2001) Precise relative positioning of multiple moving platforms using GPS carrier phase observables. University of Calgary, Calgary

Meza A, Natali MP, Fernández LI (2015) PCA analysis of the nighttime anomaly in far-from-geomagnetic pole regions from VTEC GNSS data. Earth Planets Space 67(1):1-14

Misra P, Enge P (2006) Global positioning system: signals, measurements and performance, 2nd edn. Ganga-Jamuna Press, Lincoln

Muella MT, de Paula ER, Mitchell CN, Kintner PM, Paes RR, Batista IS (2011) Tomographic imaging of the equatorial and low-latitude ionosphere over central-eastern Brazil. Earth Planets Space 63(2):129-138

Natali MP, Meza A (2011) Annual and semiannual variations of vertical total electron content during high solar activity based on GPS observations. Ann Geophys 29(5):865-873 
Parker RL (2004) Geophysical inverse theory. Princeton University Press, Princeton

Preisendorfer RW, Mobley CD (1988) Principal component analysis in meteorology and oceanography, vol 425, 1st edn. Elsevier, Amsterdam

Qian L, Solomon SC, Roble RG, Kane TJ (2008) Model simulations of global change in the ionosphere. Geophys Res Lett 35:L07811. doi:10.1029/200 7GL033156

Raghunath S, Ratnam DV (2015) Detection of low-latitude ionospheric irregularities from GNSS observations. IEEE J Sel Top Appl Earth Obs Remote Sens 8(11):5171-5176

Ratnam DV, Sarma AD (2012) Modeling of low-latitude ionosphere using GPS data with SHF model. IEEE Trans Geosci Remote Sens 50(3):972-980

Sarma AD, Ratnam DV, Reddy DK (2009) Modelling of low-latitude ionosphere using modified planar fit method for GAGAN. Radar Sonar Navig IET 3(6):609-619

Schaer S (1999) Mapping and predicting the Earth's ionosphere using the global positioning system. Geod Geophys Arb Schweiz 59:59

Schunk R, Nagy A (2009) lonospheres: physics, plasma physics, and chemistry. Cambridge University Press, Cambridge

Seeber G (2003) Satellite geodesy: foundations, methods, and applications. Walter de Gruyter, Boston

Shi H, Zhang DH, Hao YQ et al (2015) Hour-to-hour variability of the ionosphere: an application of the classical multidimensional scaling method. Sci China Earth Sci. doi:10.1007/s11430-014-5035-9
Skone SH (1998) Wide area ionosphere grid modelling in the auroral region. Ph.D. Thesis, UCGE Report No. 20123, University of Calgary, Calgary

Tanaka T (1986) Low-latitude ionospheric disturbances: results for March 22, 1979, and their general characteristics. Geophys Res Lett 13(13):1399-1402

Tapping KF (1987) Recent solar radio astronomy at centimeter wavelengths: the temporal variability of the $10.7-\mathrm{cm}$ flux. J Geophys Res Atmos 92(D1):829-838

Wu CC, Fry CD, Liu JY, Liou K, Tseng CL (2004) Annual TEC variation in the equatorial anomaly region during the solar minimum: September 1996August 1997. J Atmos Solar Terr Phys 66(3):199-207

Wu CC, Liou K, Shan SJ, Tseng CL (2008) Variation of ionospheric total electron content in Taiwan region of the equatorial anomaly from 1994 to 2003. Adv Space Res 41(4):611-616

Yeh KC, Liu CH (1982) Radio wave scintillations in the ionosphere. Proc IEEE 70(4):324-360

Zhang ML, Shi JK, Wang X, Wu SZ, Zhang SR (2004) Comparative study of ionospheric characteristic parameters obtained by DPS-4 digisonde with IRI2000 for low latitude station in China. Adv Space Res 33(6):869-873

Zhao B, Wan W, Liu L, Mao T, Ren Z, Wang M, Christensen AB (2008) Features of annual and semiannual variations derived from the global ionospheric maps of total electron content. Ann Geophys 25(12):2513-2527

\section{Submit your manuscript to a SpringerOpen ${ }^{\circ}$ journal and benefit from:}

- Convenient online submission

- Rigorous peer review

- Immediate publication on acceptance

- Open access: articles freely available online

- High visibility within the field

- Retaining the copyright to your article

Submit your next manuscript at $\boldsymbol{\nabla}$ springeropen.com 